\title{
Using data of weight tests and impedance spectroscopy to evaluate the protective effectiveness of zinc-rich oil coatings in corrosion of carbon steel
}

\section{V.I. Vigdorovich ${ }^{+1,2}$ L.E. Tsygankova, ${ }^{3}$ N.V. Shel, ${ }^{2}$ A.O. Golovchenko, ${ }^{1}$ V.V. Ostrikov ${ }^{1}$ and M.V. Vigdorowitsch ${ }^{4}$}

${ }^{1}$ All-Russian Scientific Research Institute of Use of Machinery and Oil Products, NovoRubezhnyi per., 28, Tambov, 392022, Russian Federation

${ }^{2}$ Tambov State Technical University, ul. Sovetskaya, 106, Tambov, 392000, Russian Federation

${ }^{3}$ Derzhavin State University, ul. Internatsyonalnaya, 33, Tambov, 392000, Russian Federation

${ }^{4}$ Angara GmbH, In der Steele 2, D-40599, Düsseldorf, Germany E-mail: vits21@mail.ru

\begin{abstract}
Studies have been carried out in a $3 \%$ aqueous solution of $\mathrm{NaCl}$, acidified in some cases to $\mathrm{pH}$ 3 or 4 . The protective efficacy of zinc-rich coatings based on waste motor oil has also been studied in a thermal moisture chamber and natural conditions. Partial rates of oxidation of zinc from the coating and iron are estimated on the base of chemical analysis of saline solution for $\mathrm{Zn}^{2+}$ and $\mathrm{Fe}^{2+}+\mathrm{Fe}^{3+}$ ions. The protective effect of zinc as a function of its concentration in the coating, which varies with time as a result of its anodic dissolution, is estimated. The effect of oil-zinc-containing (40, 50 and $60 \mathrm{wt} . \% \mathrm{Zn})$ coatings on the charge transfer resistance in partial electrode reactions occurring during steel corrosion has been investigated by impedance spectroscopy. It is shown that the protective effect $(Z, \%)$ of the oil compositions reaches 88,86 and $90 \%$ for corrosion tests in the chloride salt solution, thermal moisture chamber and under natural conditions, respectively. However, in $3 \% \mathrm{NaCl}$ solution it sharply decreases after a zinc concentration decrease in the oil film to 16-20\%. The charge transfer resistance in the cathodic reaction $\left(R_{\mathrm{c}}\right)$ of unprotected steel is $45 \mathrm{Ohm} \cdot \mathrm{cm}^{2}$ immediately after immersion in a solution with $\mathrm{pH} 6.5$ and decreases to $33 \mathrm{Ohm} \cdot \mathrm{cm}^{2}$ after $24 \mathrm{~h}$ exposure. When the $\mathrm{pH}$ of the corrosive medium drops to 3.0, the picture is analogous. At the initial stage, $R_{\mathrm{c}}$ equals $40 \mathrm{Ohm} \cdot \mathrm{cm}^{2}$ and decreases to $24 \mathrm{Ohm} \cdot \mathrm{cm}^{2}$ after 24 hours (in situ). The magnitude of the charge transfer resistance in the anodic reaction is 20-470 times greater than $R_{\mathrm{c}}$ under the indicated conditions. The presence of $60 \%$ zinc in the surface oil coating has a relatively weak effect on the $R_{\mathrm{c}}$ value and increases $R_{\mathrm{a}} 45-50$ fold under comparable conditions ( $\mathrm{pH}=3.0$, $24 \mathrm{~h}$ exposure). Corrosion of steel begins on the tenth day after immersion in a solution. At that the initial concentration of $\mathrm{Zn}\left(C_{\text {initial }}=60 \mathrm{wt} . \%\right)$ decreases twofold and steel corrosion rate increases with a further decrease in the zinc concentration in the oil coating.
\end{abstract}


Key words: steel, corrosion, saline solution, thermal moisture chamber, natural conditions, charge transfer resistance, anode process, cathodic reaction, protective effect.

Received: October 12, 2018. Published: March 20, 2019

doi: $\underline{10.17675 / 2305-6894-2019-8-2-4}$

\section{Introduction}

The protective efficacy of zinc-filled oil compositions based on commodity industrial I20A and waste motor oils [1-4], with additionally added carbon filler of various types (graphite, nanotubes) [2,3], has been studied previously against atmospheric corrosion of carbon steel. Such compositions, in comparison with zinc-filled coatings described in [5, 6], allow multiple re-opening and reconservation of metal products under temporary storage conditions. It is shown that the introduction of a carbon filler ( $4 \%$ by weight) in the form of micrographite (MG) together with zinc powder allows to reduce the $\mathrm{Zn}$ content from 75 to $60 \%$. Replacing the micrographite with carbon nanotubes did not lead to the appearance of a nanosized synergetic effect [2-4].

At the same time, the behavior and consumption of the zinc protector in time, the nature of the effect of its concentration in the protective film on the inhibition of partial electrode reactions on the steel and the kinetics of ionization of iron remain unclear. The use of electrochemical impedance spectroscopy method made it possible to obtain a number of valuable additional data, the interpretation of which is possible only with the use of a number of additional assumptions. So, it is not clear to which anode process the charge transfer resistance is related - the ionization of zinc, iron or both simultaneously. In addition, as the corrosion of steel proceeds over time in the $3 \% \mathrm{NaCl}$ solution the nature of the processes that occur can change significantly. But it is not reflected in the data of impedance spectroscopy, obtained in [5] at the first moments after beginning of corrosion attack.

The purpose of this work was the development of previous studies, in particular, an estimation of the dissolution rate of zinc and iron as a function of the test duration, the effect of this factor on the nature of the data obtained by electrochemical impedance method.

\section{Experimental}

Electrochemical measurements and corrosion tests were carried out on St3 carbon steel of composition, wt.\%: C 0.2; Mn 0.5; Si 0.15; P 0.04; S 0.05; Cr 0.30; Ni 0.20; Cu 0.20; Fe 98.36 in $3 \% \mathrm{NaCl}$ solution, optionally acidified with $\mathrm{HCl}$ to $\mathrm{pH}$ equal to 3 or 4 . Working electrode for electrochemical measurement with a horizontal working surface, reinforced in a mandrel made of epoxy resine ED-16 solidified with polyethylene polyamine B was polished, degreased with acetone and dried with filter paper. The samples with the size of $60 \times 30 \times 3 \mathrm{~mm}$ were used for corrosion testing and an estimation of partial rates of the 
oxidation of zinc and iron by chemical analysis of the solution for $\mathrm{Zn}^{2+}$ and $\left(\mathrm{Fe}^{2+}+\mathrm{Fe}^{3+}\right)$ ions. A duration of the experiment in the salt solution is 14 days, in the thermal moisture chamber -30 days with a work cycle: $8 \mathrm{~h}$ at $40^{\circ} \mathrm{C}$ and $100 \%$ relative humidity $(H), 16 \mathrm{~h}-$ under conditions of switched off camera and a decrease in temperature and $H$ with closed door.

Waste motor oil (WMO) was used as a binder (solvent-support, hereinafter SS). As a filler, zinc powder ( $\mathrm{Zn} 99.9 \%$ ) with the following fractional composition, $\mu \mathrm{m}, \%: 2 . .5 \sim 96$; $5 \ldots 10-4 ; 10 \ldots 20-0.01$ was used. Its concentration in the oil composition was 40,50 or $60 \%$. Dissolution of iron in the initial stages of steel corrosion was controlled by qualitative reaction with $\mathrm{K}_{4} \mathrm{Fe}(\mathrm{CN})_{6}$ and quantitatively by photocolorimetric determination with sulfosalicylic acid. The zinc(II) concentration in the solution was evaluated trilonometrically with the Eriochrome black T indicator. The oil composition coatings were deposited by immersion of the samples into the bath containing the composition at $20^{\circ} \mathrm{C}$ for 15-20 minutes. After that, the samples were kept in a suspended state at room temperature to drain the excess composition. After completion of the corrosion tests, the samples were cleaned from oil films and corrosion products, degreased, dried and weighed. The protective effect of the oil compositions was evaluated according to the formula

$$
Z, \%=100\left[\left(K_{0}-K_{\mathrm{C}}\right) / K_{0},\right.
$$

where $K_{0}$ and $K_{\mathrm{C}}$ are the corrosion rates of uncoated steel and with the protective composition, respectively. The tests were repeated from three to six times.

The density of the protective compositions necessary for calculation of the coating thickness was evaluated pycnometrically at $20^{\circ} \mathrm{C}$.

Electrochemical impedance spectroscopy measurements (Solartron 1250 FRA) were carried out in a frequency range of $10 \mathrm{kHz}-50 \mathrm{mHz}$ in a $3 \% \mathrm{NaCl}$ solution at the corrosion potential [7].

\section{Results and discussion}

The protective efficiency of a film of waste motor oil, without $(Z)$ and with zinc filler $\left(Z_{\Sigma}\right)$ under various test conditions is given in Table 1 . The $\Delta Z$ value is the contribution of the protector effect to the overall protective efficiency of the oil film and zinc filler, if we assume that their action is additive.

The protective efficiency of the film of the waste motor oil without the filler is $34 \%$ in the salt solution. This $Z$ value is due to the formation of oxidation products in the oil during its functional use, primarily, apparently, higher carboxylic acids, which are corrosion inhibitors. In the $\mathrm{NaCl}$ solution the protective effect of zinc containing oil composition is $85-86 \%$ and the fraction of the $\mathrm{Zn}$ protector is $51-52 \%$. Under the conditions of the thermal moisture chamber, where competitive adsorption of chlorine anions is absent, the protective efficiency is somewhat higher and reaches, in some cases, $88 \%$, although $\Delta Z$ 
decreases significantly and sometimes reaches $10 \%$. Under natural conditions, the protective effect does not practically differ from that in the salt solution and thermal moisture chamber, and the $\Delta Z$ value approaches the value in the salt solution. However, it is an average value, which, first of all, concerns the results obtained in the salt solution, since the concentration of zinc in the surface film due to its oxidation can vary significantly with time. In the thermal moisture chamber and under natural conditions, the oxidation of zinc occurs much more slowly due to the much lower corrosivity of the medium.

Table 1. Protective effectiveness of compositions based on waste motor oil without and with zinc filler.

$Z, \%$ at the initial content of zinc in the protective film, $\%$

\begin{tabular}{|c|c|c|c|c|c|c|c|}
\hline \multirow[t]{2}{*}{ Corrosive conditions } & \multirow{2}{*}{$\frac{\text { absent }}{Z}$} & \multicolumn{2}{|c|}{40} & \multicolumn{2}{|c|}{50} & \multicolumn{2}{|c|}{60} \\
\hline & & $\Delta Z$ & $Z_{\Sigma}$ & $\Delta Z$ & $Z_{\Sigma}$ & $\Delta Z$ & $Z_{\Sigma}$ \\
\hline $\begin{array}{l}3 \% \mathrm{NaCl} \text { solution (room } \\
\text { temperature) }\end{array}$ & 34 & 52 & 86 & 51 & 85 & 52 & 86 \\
\hline $\begin{array}{l}\text { thermal moisture } \\
\text { chamber }\end{array}$ & 63 & 25 & 88 & 10 & 73 & 25 & 88 \\
\hline $\begin{array}{c}\text { natural conditions (12 } \\
\text { months) }\end{array}$ & 44 & 36 & 80 & 41 & 85 & 47 & 91 \\
\hline
\end{tabular}

It could be assumed that as a result of $\mathrm{Zn}$ dissolution, its concentration decreases in the protective film in time, reaching zero as a limit. For the experimental verification of this assumption, the amount of oxidized metallic zinc was determined by chemical analysis for different time intervals. Then, a difference between the initial amount of $\mathrm{Zn}$ in the protective composition and a dissolved metal amount was estimated that is a residual quantity of $\mathrm{Zn}$ in the coating.

Indeed, the zinc concentration in the barrier coating, regardless of the initial $\mathrm{pH}$ value, decreases with time, reaching an almost minimum value on the 20th day of the experiment (Figure 1). We only note that the initial value of the working solution $\mathrm{pH}$ influences the course of the $C_{\mathrm{Zn}} v s . \tau$ curves.

Iron does not dissolve at all in the first 10 days, regardless of the initial $\mathrm{pH}$ value of the corrosive medium (Figure 2). Then there is a sharp jump to a corrosion rate of $\sim 0.05$ $(\mathrm{pH}=7)-0.10 \mathrm{~g} /\left(\mathrm{m}^{2} \cdot \mathrm{h}\right)(\mathrm{pH}=3)$.

The duration of the incubation period does not depend on the initial zinc concentration in the protective film and the working solution $\mathrm{pH}$ (Figure 2). The portion of metal zinc remaining in the protective film at which iron oxidation begins (the corrosion rate is not zero), on the contrary, depends on the initial $C_{\mathrm{Zn}}$ and the $\mathrm{pH}$ of the corrosive medium. The value of $C_{\mathrm{Zn} \text {,crit }}$ is easily estimated from a comparison of the data shown in 
Figures 1 and 2. In the first approximation, it equals the $C_{\mathrm{Zn}}$ remaining in the protective film after 10 days of exposure to the sodium chloride solution. Under natural conditions, the protective effect of zinc-filled compositions based on the waste motor oil reaches $91 \%$ (40 and 60\% Zn) for 12 months exposure (June 2009 - July 2010). Its value is $96 \%$ for 9 months, while $Z$ of WMO coating without $Z n$ powder is close to $40 \%$ for this period.
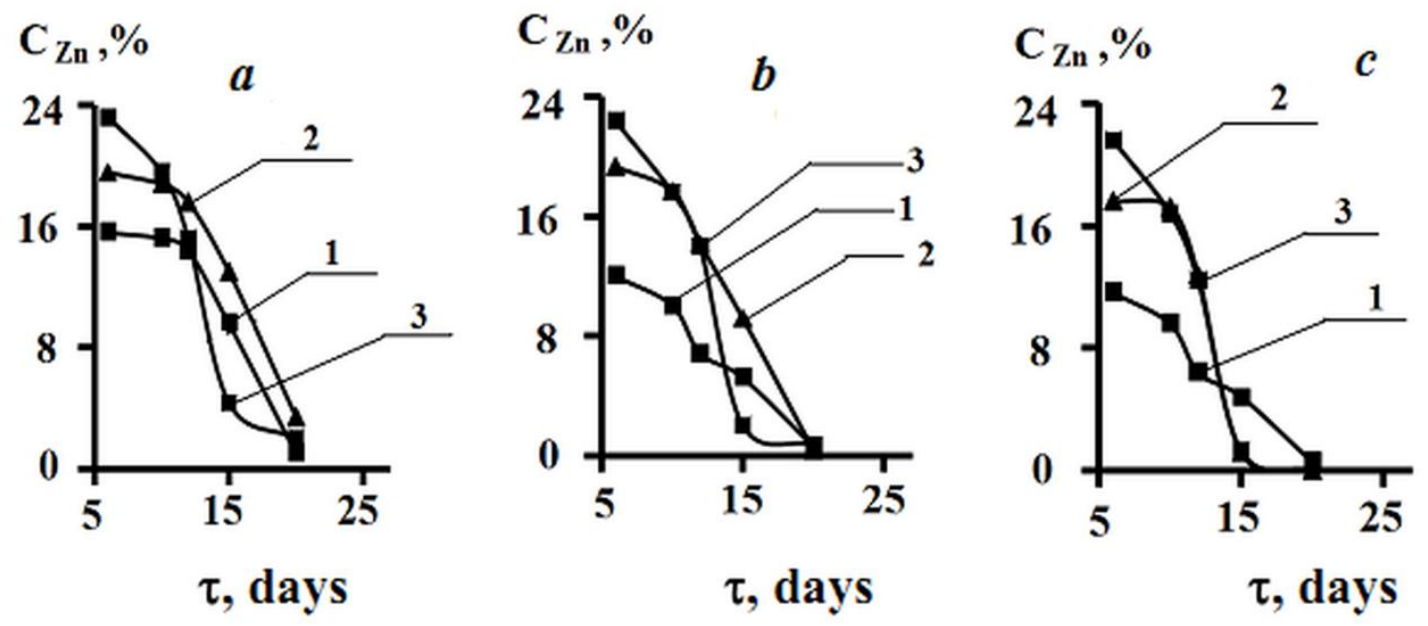

Figure 1. Dependence of the concentration of zinc remaining in the protective film in the process of corrosion of steel coated with a protective composition based on the waste motor oil in the $3 \% \mathrm{NaCl}$ solution, on the test duration. Initial zinc concentration in the protective film, $\%: 1-40 ; 2-50 ; 3-60$. Initial $\mathrm{pH}$ of the working solution: $\mathrm{a}-6.5 ; \mathrm{b}-4 ; \mathrm{c}-3$.
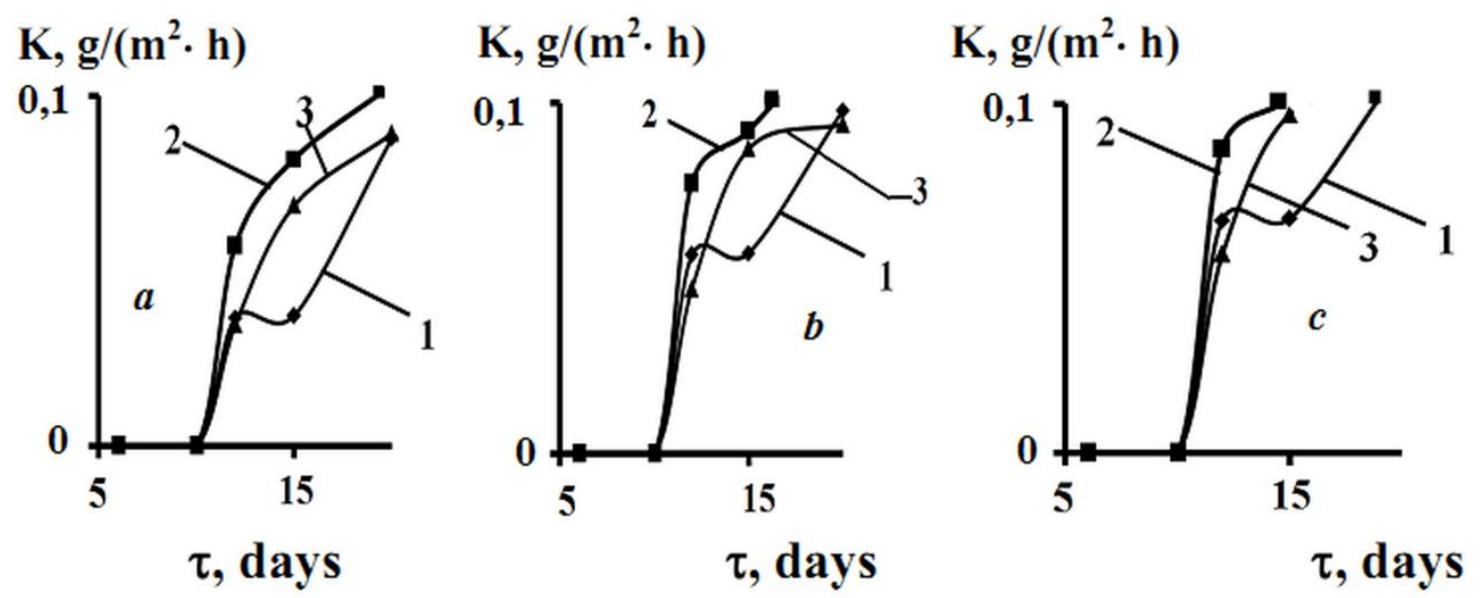

Figure 2. Effect of the test duration on the corrosion rate of steel protected by a composition based on the waste motor oil with an initial zinc concentration, $\%: 1-40 ; 2-50 ; 3-60$. Steel corrosion rate was calculated on base of concentration of dissolved iron (according to the chemical analysis data). The initial $\mathrm{pH}$ value of the working solution: $\mathrm{a}-6.5 ; \mathrm{b}-4 ; \mathrm{c}-3$. 
Carrying out electrochemical studies of steel protected by zinc-filled coatings in highly corrosive environments is difficult, since both the state of the steel surface and the composition of the surface oil film vary with time. Interpretation of data obtained by impedance spectroscopy method also encounters additional difficulties. They are caused by the corrosion of the bimetallic iron/zinc system, inducing the parallel dissolution of zinc and iron. In this case, the charge transfer resistance in the anodic reaction can refer to either of the metals. And if ionization of zinc under similar conditions is planned, then the oxidation of iron is an adverse corrosion process.

Under the conditions of the experiment, iron is practically not oxidized for the first ten days, since $\mathrm{Fe}^{2+}$ ions can not be detected in solution even qualitatively by the reaction with $\mathrm{K}_{4}\left[\mathrm{Fe}(\mathrm{CN})_{6}\right]$. This significantly facilitates an interpretation of the results obtained in the first period of the operation of the system containing the second indifferent metal, since the cathodic and anodic reactions refer only to zinc corrosion during this period. In contrast, in the absence of the protective coating, all the data of the equivalent circuit characterizing the charge transfer resistance in the partial electrode reactions are related only to the corrosive behavior of iron.

An exception is the value of the capacitance of the double electrical layer, that apparently characterizes some average parameter related to both metals of the bimetallic system. However, taking into account the large surface area of microstructured $\mathrm{Zn}$ compared with iron, we can assume that $C_{\mathrm{dl}}$ also characterizes the capacitance of the double electrical layer of the zinc component.

The equivalent circuit in Figure 3a was used to analyze the impedance spectra of still samples without oil composition coatings.

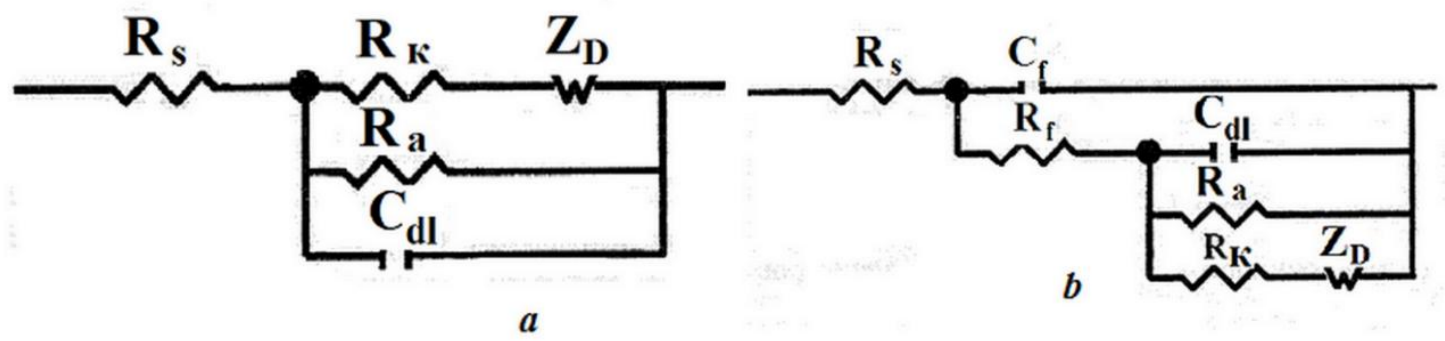

Figure 3. Equivalent circuit used in the study of the electrochemical characteristics of steel corrosion without (a) and with a zinc-filled oil coating (b).

Here $R_{\mathrm{s}}$ is the resistance of the solution, $R_{\mathrm{a}}$ and $R_{\mathrm{c}}$ are the charge transfer resistance in the anodic and cathodic reactions, respectively, $C_{\mathrm{dl}}$ is the double-layer capacitance, and $Z_{\mathrm{D}}$ is the finite impedance of diffusion of cathodic depolarizers:

$$
Z_{\mathrm{D}}=R_{\mathrm{D}} t h(j \omega \tau)^{1 / 2} /(j \omega \tau)^{1 / 2},
$$


where $R_{\mathrm{D}}=R T \delta /\left(n^{2} F^{2} c_{x=0} D\right)$ is the mass transfer resistance, $\tau=\delta^{2} / D$ is the characteristic diffusion time, $\delta$ is the diffusion layer thickness, $D$ is the diffusion coefficient, and $C_{x=0}$ is the surface concentration of electroactive particles. The equivalent circuit for steel coated with a zinc containing waste oil composition is shown in Figure $3 \mathrm{~b}$. The elements $C_{\mathrm{f}}$ and $R_{\mathrm{f}}$ characterizing respectively the capacitance and resistance of the solution in the pores of the film are additionally introduced. Both equivalent circuits were used earlier in $[7,8]$ where a more detailed explanation can be found.

The Nyquist diagrams of unprotected steel in solutions with $\mathrm{pH} 6.5$ and 3 are shown in Figure 4 and those with the protective coating, in Figure 5.
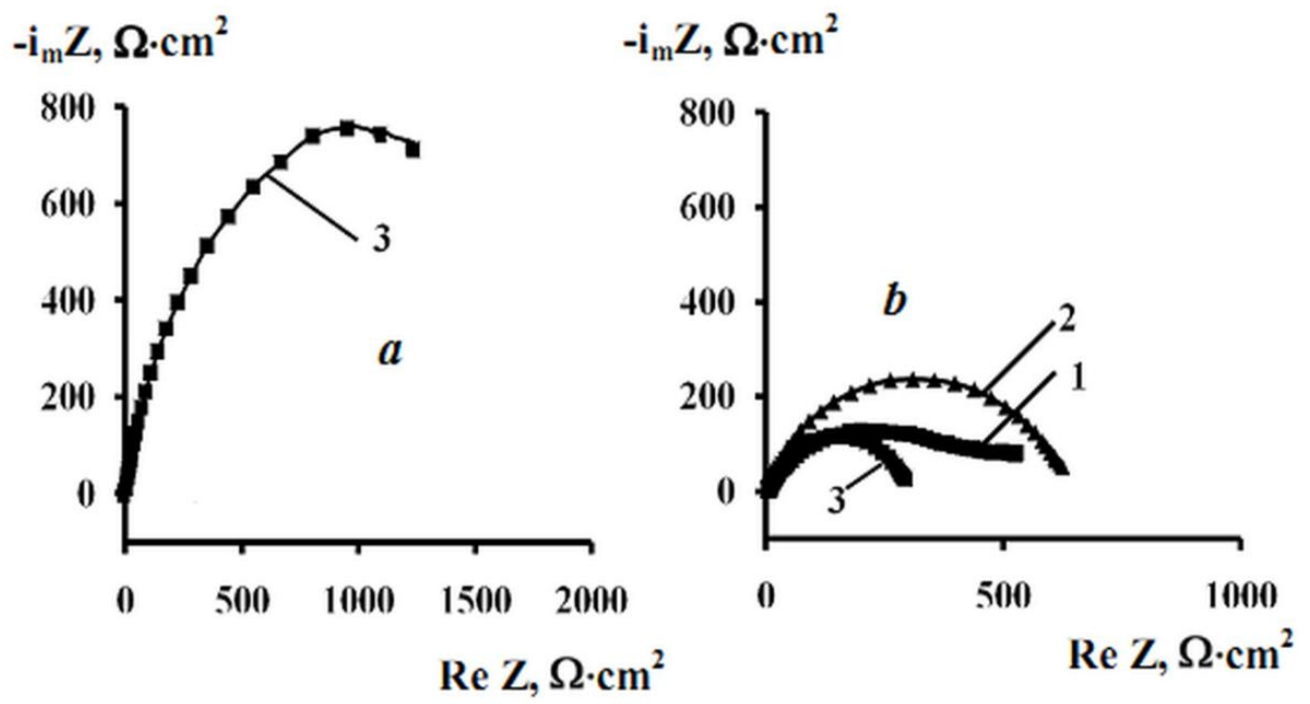

Figure 4. Nyquist plots of unprotected steel in $3 \% \mathrm{NaCl}$ solution with $\mathrm{pH}=6.5$ (a) and $\mathrm{pH}=3$ (b) for the duration of the test, h: $1-0 ; 2-6 ; 3-24$.

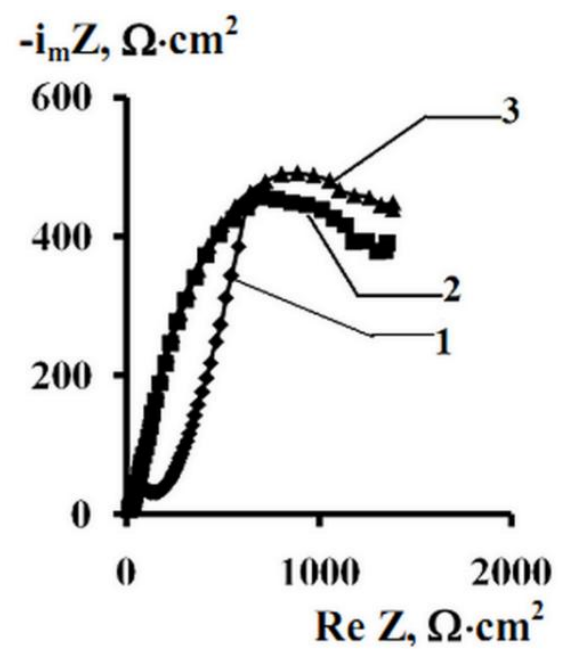

Figure 5. Nyquist plots of St3 steel protected by waste motor oil coating in $3 \% \mathrm{NaCl}$ solution with $\mathrm{pH}=6.5$ for the duration of the test, h: $1-0 ; 2-6 ; 3-24$. 
The frequency spectra of the impedance (Nyquist diagram) for St3 steel at the corrosion potential under the investigated conditions have the form of distorted stretched segments, a result of overlapping of two or more circles. The dots on the curves correspond to the experimental data and the solid lines correspond to the calculated values based on the equivalent circuit used. The values of the equivalent circuit parameters for the unprotected steel observed in the first day of corrosion are given in Table 2. The values observed in the solution with $\mathrm{pH}=6.5$ are practically the same as those given in [8].

Table 2. The values of the equivalent circuit (Figure 3a) parameters for unprotected steel in $3 \% \mathrm{NaCl}$ solution.

Aging in a solution with $\mathrm{pH}$ :

\begin{tabular}{|c|c|c|c|c|c|c|}
\hline \multirow{3}{*}{$\begin{array}{l}\text { Equivalent circuit } \\
\text { parameter }\end{array}$} & \multirow{2}{*}{\multicolumn{3}{|c|}{6.5}} & \multirow{2}{*}{\multicolumn{3}{|c|}{3.0}} \\
\hline & & & & & & \\
\hline & $C^{*}$ & $6 \mathrm{~h}$ & $24 \mathrm{~h}$ & $C$ & $6 \mathrm{~h}$ & $24 \mathrm{~h}$ \\
\hline$C_{\mathrm{dl}}, \mu \mathrm{F} / \mathrm{cm}^{2}$ & 51 & 58 & 56 & 58 & 60 & 56 \\
\hline$R_{\mathrm{a}}, \Omega \cdot \mathrm{cm}^{2}$ & 940 & 1280 & 15530 & 1520 & 3200 & 322 \\
\hline$R_{\mathrm{c}}, \Omega \cdot \mathrm{cm}^{2}$ & 45 & 28 & 33 & 40 & 17 & 24 \\
\hline$R_{\mathrm{a}} / R_{\mathrm{c}}$ & 21 & 46 & 471 & 38 & 188 & 13.4 \\
\hline$R_{\mathrm{D}}, \Omega \cdot \mathrm{cm}^{2}$ & 8570 & 5340 & 6820 & 14050 & 5900 & 1360 \\
\hline$R_{\mathrm{D}} / R_{\mathrm{a}}$ & 9.1 & 42 & 0.44 & 9.2 & 0.19 & 4.2 \\
\hline
\end{tabular}

${ }^{*} C$ - here and below, immediately after immersion of a steel electrode into the solution.

According to Table $2, R_{\mathrm{c}}<<R_{\mathrm{a}}$ and $R_{\mathrm{c}}<<R_{\mathrm{D}}$. The $R_{\mathrm{a}} / R_{\mathrm{D}}$ value depends on the test duration $(\tau)$. This value is less than 1 at $\tau \leq 6$ and at $\tau=24 \mathrm{~h} \mathrm{R}_{\mathrm{D}}<\mathrm{R}_{\mathrm{a}}$.

An increase in acidity to $\mathrm{pH}=3$ (Table 2) is characterized by the $R_{\mathrm{D}}>R_{\mathrm{a}}$ ratio. Such a picture permits to suppose that zinc dissolves at $\mathrm{pH}=3$ without a significant contribution of hydrogen depolarization, which is due to high hydrogen overvoltage on this cathode [9]. In addition, the potential of zinc is significantly increased due to the effect of iron. The proximity of the $C_{\mathrm{dl}}$ values for various $\tau$ and $\mathrm{pH}$ (Table 2) indicates that the state of the surface of the steel (apparently of both metals) is practically unchanged. The values of the equivalent circuit parameters for the steel covered by the waste motor oil film $(90 \mu \mathrm{m})$ are shown in Table 3.

In the presence of the WMO oil film, the double-layer capacity of steel decreases 712 fold, but steel nevertheless corrodes with a noticeable rate in the salt solution ( $Z$ of films does not exceed 34\% (Table 1)). The charge transfer resistance in the cathodic reaction remains practically unchanged (except for the solution with $\mathrm{pH}=6.5$ at $\tau \sim 0$ (immediately after immersion of the metal into the solution), when $R_{\mathrm{c}}$ increases to 180). However, due to 
the inequalities $R_{\mathrm{c}} \ll<R_{\mathrm{a}}$ and $R_{\mathrm{c}} \ll<R_{\mathrm{D}}$, the charge transfer resistance $R_{\mathrm{c}}$ does not determine the corrosion rate of steel, which is controlled by the kinetics of the anode process for some $\tau$, while for other $\tau(\tau \geq 6)$ - by the mass transfer of dissolved oxygen as a cathodic depolarizer to the surface of corroding steel.

Table 3. The value of the parameters of the equivalent circuit (Figure 3b) for corrosion of steel with a protective film of the $\mathrm{WMO}$ in the $3 \% \mathrm{NaCl}$ solution.

Aging in a solution with pH:

\begin{tabular}{ccccccc}
\cline { 2 - 7 } $\begin{array}{c}\text { Equivalent circuit } \\
\text { parameter }\end{array}$ & \multicolumn{3}{c}{$\mathbf{6 . 5}$} & $\mathbf{3}$ & $\mathbf{3 . 0}$ \\
\cline { 2 - 7 } & 5 & $\mathbf{6} \mathbf{h}$ & $\mathbf{2 4} \mathbf{~ h}$ & $\boldsymbol{C}$ & $\mathbf{6 ~ h}$ & $\mathbf{2 4} \mathbf{~ h}$ \\
\hline$C_{\mathrm{dl}}, \mu \mathrm{F} / \mathrm{cm}^{2}$ & 5 & 2 & 2 & 5 & 8 & 5 \\
$R_{\mathrm{a}}, \Omega \cdot \mathrm{cm}^{2}$ & 77400 & 1690 & 1800 & 4160 & 236 & 350 \\
$R_{\mathrm{c}}, \Omega \cdot \mathrm{cm}^{2}$ & 180 & 45 & 23 & 33 & 54 & 19 \\
$R_{\mathrm{a}} / R_{\mathrm{c}}$ & 430 & 2020 & 590 & 126 & 4.37 & 18.42 \\
$R_{\mathrm{D}}, \Omega \cdot \mathrm{cm}^{2}$ & 2330 & 2780 & 6850 & 850 & 900 & 9000 \\
$R_{\mathrm{D}} / R_{\mathrm{a}}$ & 0.01 & 0.12 & 1.16 & 0.2 & 3.81 & 25.7 \\
\hline
\end{tabular}

In a presence of the zinc-filled WMO film, the situation changes: iron becomes, as noted above, an indifferent metal, as the rate of its corrosion decreases sharply as a result of the cathodic displacement of the steel potential, and the anodic and cathodic reactions are realized as the conjugated processes of zinc dissolution. The values of the equivalent circuit parameters observed during the first day of corrosion of $\mathrm{Zn}$ are given in Tables 4 (40\% zinc) and 5 (60\% zinc in the oil composition).

With a smaller protector concentration and $\mathrm{pH}=6.5$ (Table 4), as before, in the absence of $\mathrm{Zn}$, the $R_{\mathrm{c}}<<R_{\mathrm{a}}$ and $R_{\mathrm{c}} \ll<R_{\mathrm{D}}$ inequalities are valid. And in the initial period of exposure to corrosive medium $R_{\mathrm{a}}$ is very large, but it quickly decreases in time, probably due to dissolution of the surface oxide film or its modification. Again in the initial period of corrosion $R_{\mathrm{a}}>R_{\mathrm{D}}$ (Table 4 ), but already by $\tau=6 \mathrm{~h}$ this inequality reverts and $R_{\mathrm{D}}$ rapidly increases with time. 
Table 4. The values of the parameters of the equivalent circuit (Figure 3b) for steel with the zinc filled WMO coating on its surface ( $40 \%$ zinc).

Aging in a solution with pH:

\begin{tabular}{ccccccc}
$\begin{array}{c}\text { Equivalent circuit } \\
\text { parameter }\end{array}$ & \multicolumn{3}{c}{$\mathbf{6 . 5}$} & $\mathbf{C . 0}$ & $\mathbf{3 . 0}$ & \\
\cline { 2 - 7 } & 4 & 4 & 3 & 15 & 6 & 10 \\
\hline$C_{\mathrm{d} l}, \mu \mathrm{F} / \mathrm{cm}^{2}$ & 112000 & 3900 & 3000 & 278000 & 24000 & 16600 \\
$R_{\mathrm{a}}, \Omega \cdot \mathrm{cm}^{2}$ & 41 & 70 & 158 & 24 & 400 & 27 \\
$R_{\mathrm{c}}, \Omega \cdot \mathrm{cm}^{2}$ & 2731 & 56 & 19 & 11500 & 60 & 614 \\
$R_{\mathrm{a}} / R_{\mathrm{c}}$ & 1800 & 7000 & 11300 & 4600 & 4500 & 3300 \\
$R_{\mathrm{D}}, \Omega \cdot \mathrm{cm}^{2}$ & 0.01 & 1.8 & 3.76 & 0.016 & 0.18 & 0.2 \\
$R_{\mathrm{D}} / R_{\mathrm{a}}$ & & & & & & $\mathbf{6 4} \mathbf{~ h}$ \\
\hline
\end{tabular}

Table 5. The values of the parameters of the equivalent circuit (Figure 3b) for steel with the zinc filled WMO coating on its surface ( $60 \%$ zinc).

Aging in a solution with pH:

\begin{tabular}{ccccccc}
\cline { 2 - 7 } $\begin{array}{c}\text { Equivalent circuit } \\
\text { parameter }\end{array}$ & \multicolumn{3}{c}{$\mathbf{6 . 5}$} & $\mathbf{6}$ & $\mathbf{3 . 0}$ & \\
\cline { 2 - 7 } & 5 & 1 & 2 & 11 & 10 & 1 \\
\hline$C_{\mathrm{dl}}, \mu \mathrm{F} / \mathrm{cm}^{2}$ & 15000 & 3800 & 2800 & 316 & 11000 & 16900 \\
$R_{\mathrm{a}}, \Omega \cdot \mathrm{cm}^{2}$ & 100 & 75 & 24 & 56 & 42 & 46 \\
$R_{\mathrm{c}}, \Omega \cdot \mathrm{cm}^{2}$ & 150 & 50 & 116 & 5,64 & 261 & 367 \\
$R_{\mathrm{a}} / R_{\mathrm{c}}$ & 2400 & 14000 & 26000 & 4300 & 2250 & 3500 \\
$R_{\mathrm{D}}, \Omega \cdot \mathrm{cm}^{2}$ & 0.16 & 3.68 & 9.28 & 13.6 & 0.2 & 0.2 \\
$R_{\mathrm{D}} / R_{\mathrm{a}}$ & & & & & & $\mathbf{6} \mathbf{~ h}$ \\
\hline
\end{tabular}

This behavior can be explained as follows. In the presence of zinc, the process is associated with solely its oxidation, which proceeds at a faster rate than iron dissolution (in the absence of a zinc-containing coating). This leads to a higher consumption of dissolved oxygen, since the process proceeds with oxygen depolarization. Accordingly, the concentration of $\mathrm{O}_{2}$ in the diffusion layer falls and $\mathrm{R}_{\mathrm{D}}$ increases. The capacitance of the double electrical layer in the presence of the zinc containing coating is practically unchanged, and its low value $\left(3-4 \mu \mathrm{F} / \mathrm{cm}^{2}\right)$ is due to the sorption of the inhibitors from the waste motor oil. In a more acidic corrosive environment, $R_{\mathrm{D}}$ is appreciably reduced. This is 
apparently due to a change in the nature of the surface film on zinc, or its almost complete dissolution, in particular, due to the reaction

$$
\mathrm{ZnO}+2 \mathrm{H}^{+} \rightarrow \mathrm{Zn}^{2+}+\mathrm{H}_{2} \mathrm{O} .
$$

Facilitating a diffusion of dissolved oxygen to the corroding surface of the protector takes place too (the oxidation rate of iron at the same values of $\tau$ is close to zero).

However, acidification of the medium leads to a significant increase in the charge transfer resistance in the anodic reaction and to the $R_{\mathrm{a}}>R_{\mathrm{D}}$ inequality (Table 4). In general, almost the same picture is observed with an increase in the zinc concentration up to $60 \%$ (Table 5). It is not possible to interpret the significant increase in $R_{\mathrm{a}}$ in the media with $\mathrm{pH}=$ 3 without additional assumptions. First, according to our data, the rate of $\mathrm{Zn}$ anodic reaction decreases with a decrease in $\mathrm{C}_{\mathrm{OH}}{ }^{-}$, as it is typical for iron. Second, it is impossible to exclude a contribution of hydrogen depolarization and surface blocking by the evolving hydrogen. In general, this issue requires additional research.

It was of undoubted interest to find out how the parameters of the equivalent circuit vary, characterizing the kinetics of partial electrode reactions after the complete dissolution of zinc from the protective oil composition coating. For this purpose, the electrode covered with a coating containing $40 \%$ zinc was kept in the working solution for the certain time (20 days) without changing the $\mathrm{pH}$ and salt concentration. During this period virtually all the initial zinc has passed into the corrosive medium from the oil protective coating. Simultaneously, at the end of the given test interval, only steel corrodes with high rate (Figure 2). The corresponding parameters of the equivalent circuit obtained after 20 days of the corrosion test are given in Table 6 .

Table 6. The parameters of the equivalent circuit (Figure 3a) for steel with the zinc filled WMO coating containing $40 \%$ zinc after 20 days of exposure in a corrosive environment.

\begin{tabular}{ccc}
\hline \multirow{2}{*}{$\begin{array}{c}\text { Equivalent circuit } \\
\text { parameter }\end{array}$} & \multicolumn{2}{c}{ Aging in a solution with $\mathbf{p H :}$} \\
\cline { 2 - 3 } & $\mathbf{6 . 5}$ & $\mathbf{3 . 0}$ \\
\hline$C_{\mathrm{d} 1}, \mu \mathrm{F} / \mathrm{cm}^{2}$ & 1.5 & 0.6 \\
\hline$R_{\mathrm{a}}, \Omega \cdot \mathrm{cm}^{2}$ & 976 & 4550 \\
$R_{\mathrm{c}}, \Omega \cdot \mathrm{cm}^{2}$ & 15 & 209 \\
$R_{\mathrm{a}} / R_{\mathrm{c}}$ & 65 & $\sim 22$ \\
$R_{\mathrm{D}}, \Omega \cdot \mathrm{cm}^{2}$ & 1985 & 81160 \\
$R_{\mathrm{D}} / R_{\mathrm{a}}$ & $\sim 2$ & $\sim 18$ \\
\hline
\end{tabular}

It should be noted that the qualitative picture is practically unchanged. Again, at $\mathrm{pH}=$ $6.5, R_{\mathrm{a}}>R_{\mathrm{c}}$ and $R_{\mathrm{D}}>R_{\mathrm{a}}$. Consequently, the process is still controlled by the supply of 
dissolved oxygen as a cathodic depolarizer to the corroding surface. The value of $C_{\mathrm{dl}}$ is of the order of $1 \mu \mathrm{F} / \mathrm{cm}^{2}$. Consequently, on the surface of steel, the same inhibitors are adsorbed from the oil phase as on $\mathrm{Zn}$. This is all the more likely that usually corrosion inhibitors of iron and carbon steel tend to slow down the corrosion of zinc, for all the dissimilarity of these metals [10]. When the corrosive medium is acidified, the charge transfer resistance in anodic reaction and in mass transfer resistance increases manifold (Table 6). The substantial increase in $R_{\mathrm{a}}$ is apparently due to a significant increase of a surface coverage by the products of the anodic reaction, and the formation of a polymolecular film is also possible. In favor of such an interpretation, an increase in the value of $R_{\mathrm{f}}\left(1650 \Omega \cdot \mathrm{cm}^{2}\right)$ and $C_{\mathrm{f}}\left(500 \mu \mathrm{F} / \mathrm{cm}^{2}\right)$ also testifies. However, the corrosion of steel is still limited by diffusion of dissolved oxygen. Moreover, there is a multiple increase in the $R_{\mathrm{D}}$ value (Table 6), caused by a decrease in the solubility of oxygen in the acidic medium and the difficulty of its supply to the corroding surface due to the film of anode reaction products.

\section{Conclusions}

1. In the saline solution in the $\mathrm{pH}$ range of $6.5-3$, only zinc is initially oxidized at the corrosion potential. Its complete transition from the protective film to the aqueous corrosive medium is observed on the twentieth day.

2. The corrosion of steel begins after the tenth day of exposure in the solution as a result of a twofold reduction in the concentration of zinc in the protective oil film, and its rate increases in time with decreasing content of the zinc protector.

3. The dissolution of $\mathrm{Zn}$ from oil composition is controlled by the diffusion supply of dissolved oxygen in both neutral and acidified media (at least after six hours from the start of the experiment).

4. Corrosion of steel under the oil coating after the termination of the protective action of zinc is also controlled by the supply of dissolved oxygen.

\section{Acknowledgements}

The experimental results were obtained using the equipment of the Center for Collective Use of Scientific Equipment of TSU named after G.R. Derzhavin.

The study was carried out with funding from the Russian Science Foundation, project No. 18-16-00006.

\section{References}

1. L.E. Tsygankova, V.I. Vigdorovich and S.Yu. Paramonov, Korroz.: Mater., zashch., 2004, no. 3, 30 (in Russian).

2. V.I. Vigdorovich, L.E. Tsygankova, S.Yu. Paramonov and I.Yu. Minina, Praktika Protivokorroz. Zashch., 2007, 45, no. 3, 34 (in Russian). 
3. V.I. Vigdorovich and A.O. Golovchenko, Kondensirovannye sredy $i$ mezhphaznye granitsy, 2009, 11, no. 2, 114 (in Russian).

4. V.I. Vigdorovich, A.O. Golovchenko and N.V. Shel, Korroz.: Mater., zashch., 2010, no. 2, 41 (in Russian).

5. I.V. Frishberg, O.Yu. Subbotina, O.N. Pavlyukova and V.G. Lisovskikh, Praktika Protivokorroz. Zashch., 2004, 32, no. 2, 26 (in Russian).

6. T.N. Ostanina, V.M. Rudoy, O.V. Yaroslavtseva, N.V. Shtyrba, A.S. Soloviev and O.Yu. Subbotina, Materialy nauchnoi i tekhnicheskoi konferentsii "Problemy Khimii i Khimicheskoi Tekhnologii”, 2003, Tambov, 146-148 (in Russian).

7. V.I. Vigdorovich, N.V. Shel, L.E. Tsygankova and P.N. Bernatsky, Int. J. Corros. Scale Inhib., 2015, 4, no. 3, 210. doi: 10.17675/2305-6894-2015-4-3-210-220

8. L.E. Tsygankova, V.I. Vigdorovich, Ya.R. Kim and V.I. Kichigin, Korroz.: Mater. zashch., 2008, no. 1, 37 (in Russian).

9. A.N. Frumkin, B.S. Bagotsky, Z.A. Iofa and B.N. Kabanov, Kinetika elektrodnykh protsessov (Kinetics of electrode processes), Moscow, Moscow State University, 1952 (in Russian).

10. V.I. Vigdorovich, Dissertation (Doctor of Chemical Sciences), 1991, Tambov (in Russian). 